\title{
Effects of Social Support and Socioeconomic Status on Mental Health in College Students
}

\author{
Chaurasia, $\mathrm{K}^{1}{ }^{*}$
}

\section{ABSTRACT}

Mental Health plays a very significant role to decide the quality of life. In the present competitive scenario students feel stress and face mental illness which is becoming very severe with time. In present investigation effort has been made to ascertain the effect of Social Support and Socioeconomic Status on Mental health in College Students. A 2x3 factorial design was employed. The two factors studied were: Social Support (varied at two level high and low) and socioeconomic status (varied at three level high, middle \& low). There were six cells with 30 subjects in each cell (total sample consisted of 180 subjects and age range 18-22 years). Measurement of Mental Health was furnished through Mental Health Battery developed by Arun Kumar Singh \& Alpnana Sen Gupta. Social Support and Socioeconomic status was also collected by a self-made questionnaire. Result: Result of ANOVA show the main effect of Social support and Socioeconomic Status were found significant $(\mathrm{p}<.01)$ on total mental health scores.

Keywords: Mental Health, Social Support And Socioeconomic Status.

Mental health is a central determinant to decide the quality of life. A growing body of evidence indicates that mental disorders are becoming increasingly numerous and serious among college students in developing countries like India. India has one of the highest suicide rates in the world and recent studies suggest about 40 percent are adolescents. At least 125 people aged 29 years or below are committing suicide every day and 51 per cent of the total suicide victim are graduates, college students or younger (Times of India, 2010). Mental health is an expression of emotions and signifies a successful adaptation to a range of demands. The World Health Organization defines mental health as "a state of well-being in which the individual realizes his or her own abilities to cope with the normal stresses of life and working productively so that he or she will be able to make a contribution to his or her community." WHO stresses that mental health "is not just the absence of mental disorder". Mental health refers to a person's health of

\footnotetext{
${ }^{1}$ Guest Faculty, Department of Psychology,Dr. Hari Singh Gour Central University, Sagar, MP, India

*Responding Author

Received: December 27, 2016; Revision Received: January 18, 2017; Accepted: January 27, 2017

(C) 2017 Chaurasia K; licensee IJIP. This is an Open Access Research distributed under the terms of the Creative Commons Attribution License (www.creativecommons.org/licenses/by/2.0), which permits unrestricted use, distribution, and reproduction in any Medium, provided the original work is properly cited.
} 
the mindedness. Good mental health can enhance one's life, while poor mental health can prevent someone from living a normal life. The consequences of these problems are likely to be significant and lasting, as mental disorders in early adulthood are associated with alcohol and substance abuse (Angst, 1996; Weitzman, 2004), academic success (Kessler, Foster, Saunders, \& Stang, 1995), and future employment and relationships (Ettner, Frank, \& Kessler, 1997; Kessler, Walters, \& Forthofer, 1998). Also without emotional support, mental health is at risk. Mental health of a person depends on Social support such as family, friends, relatives and socioeconomic status.

\section{Mental health and Social support}

Social support is the physical and emotional comfort given to us by our family, friends, coworkers and others. Friends, family, and significant others can provide instrumental, informational, or emotional assistance (House, Umberson, \& Landis, 1988). This assistance is commonly referred to as social support and is considered a psychosocial coping resource that positively affects individuals' personal resources such as self-esteem and self-efficacy and buffers the negative effects of stress (Thoits, 1995).

There is good evidence that social support plays an important role in mental health or substance use problems. For example, people who are clinically depressed report lower levels of social support than people who are not currently depressed. Two types of social support: the structural and functional social support. Structural support refers to the existence and quantity of relationships, whereas functional support refers to the perceived quality of social relationships. Both structural and functional social support have been found to be associated with mental health (Seeman, 1996; Son, Lin, \& George, 2008; Thoits, 1995).

Understanding the relationship between mental health and social support is of particular importance among college student populations. The recently defined period of emerging adulthood (18 -25 years of age) is characterized by change and exploration and is a crucial time for identity development (Amett, 2000). During this period of transition to adulthood, and youth attend some form of postsecondary educational institution. These students face an entirely new social environment characterized by greater freedom and less adult supervision (Lefkowitz, 2005) and frequently report homesickness, friend sickness, a sense of isolation, and increased interpersonal conflict (Boute et al., 2007).

Social support can influence emotional health and wellbeing (Kawachi \& Berkman, 2001). An extensive literature, examining a variety of populations, documents strong associations between social support and mental health (Berkman, Glass, Brissette, \& Seeman, 2000; Caron, Latimer, \& Tousignant, 2007; Coyne \& Downey, 1991; House et al., 1988; Kawachi \& Berkman, 2001; Leung, Chen, Lue,\& Hsu, 2007; Seeman, 1996; Thoits, 1995). For example, psychologically distressed persons are consistently found to be more socially isolated (Kawachi \& Berkman, 
Effects of Social Support and Socioeconomic Status on Mental Health in College Students

2001; Seeman, 1996), and less contact with friends, lack of a partner or someone to confide in, and feeling alone are also correlated with higher levels of psychological distress (Coyne \& Downey, 1991; Durden, Hill, \&Angel, 2007; Stravynski, \& Boyer, 2001). Recently social support was found to have a stronger relationship with psychological distress than conditions of poverty (Caron et al., 2007).

\section{Mental health and Socio-economic status}

Socioeconomic status is commonly conceptualized as the social standing or class of an individual or group. It is often measured as a combination of education, income and occupation. Mental health, health status and socioeconomic status are important determinants of an individual's wellbeing. Lower socioeconomic status is associated with decreased social network size and lower social integration (House et al., 1988; Thoits, 1995). Poor health and poor mental health can reduce earnings ability, through their effects on education and employment, and poverty can lead to lower educational attainment, poorer physical health and depression.

Das et al. (2007) examine the correlates of mental health in five developing countries, finding that being older, female, widowed, and in poor physical health are consistently related to poorer mental health outcomes. . However, their reading of their evidence on the relationship between socio-economic status (SES) and mental health is mixed. They find education to be positively associated with better mental health in a majority (but not all) of the countries that they study. A survey of 11 smaller community based studies in six low and middle income countries finds a negative association between education and common mental disorders in all but one study (Patel \& Kleinman 2003). Results for other indicators of socioeconomic status such as employment and income were more mixed.

Both mental health and somatic health show a social gradient, with the prevalence of illness increasing by a decreasing socio-economic status (Dalgar 2008 \&koster et al. 2006). A low socio-economic status is also associated with low social support, and a lack of support explains some of social gradient in mental health. Especially in older adults, a deterioration in financial status is known to be a stressful event, and those who are economically disadvantaged more likely to experience persistent depressive symptoms (Morjtabai\&Olfsonm2009).Therefore, socio-economic status was taken into consideration as a possible confounder when analysing the relationship between social support and psychological distress, with income maintaining its position as an independent protective factor for psychological distress, also when adjusted for health and social support in the final multivariate model. Associations between education, marital status, district of town and psychological distress become non-significant in the multivariate analyses when adjusting for all items. This confirms the assumption that financial strain is a source of psychological distress for many older adults (Rostadet al. 2009, Ferraro 1999) and that the challenge of social inequalities in health is also present in the elder age groups.

(C) The International Journal of Indian Psychology, ISSN 2348-5396 (e) | ISSN: 2349-3429 (p) | 
In this material, the odds ratio is 3 for economic problem for experiencing high levels of psychological distress among those with poor somatic health (level of significance 1 percent). In planning structural initiatives targeting psychological distress as a public health issue, it is important to avoid less involved than those who are better socially positioned. This implies that such activities should be free of charge.

\section{Purpose of the study:}

This study aimed to examine the effects of social support and socio-economic status on mental health through mental health battery by Singh et.al.

\section{Research Design:}

Researcher wishes to know the impact of social support and socioeconomic status of college students. To study two independent variables (social support \& socioeconomic status). A 2x3 factorial designed is employed. In this study one variable has 2 levels and second variable has 3 levels, there are 6 conditions. Researcher randomly allotted 30 subjects for all 6 conditions.

\section{Sample:}

The sample is consisted of one eighty male/female students of college students in sagar with age range 18-22 years old. Subjects were recruited through random sampling.

\section{Material:}

Mental health battery developed by Arun Kumar Singh \& Alpana Sen Gupta is well known as mental health was found most suitable to meet the objectives of present work. Social Support and Socioeconomic status was also collected by a self-made questionnaire.

\section{Procedure:}

One Eighty subjects are drawn from various college students of sagar, through random sampling and they are assigned into 6 sub-group. After that consent of the subjects, has been sought. Mental Health Battery by Singh et.al, has been administered to all 180 subjects for data collection. The collection of data planned systematically.

\section{RESULT}

Analysis of variance of test scores indicate that the main effect of social support (high social support $=87.18 /$ low social support $=78.12$ ) was significant $\mathrm{F}(1,174) 11.06 \mathrm{P}<.01$. (Table 1 , 2)The main effect of Socio-economic status (high SES=93.38/Middle SES-=82.68/Lowe SES= 71.89) was significant $\mathrm{F}(2,174) 20.70 \mathrm{P}<.01$. (Table 1, 2) 
Effects of Social Support and Socioeconomic Status on Mental Health in College Students

Table 1: Showing Mean \&SDs of Mental Health scores

\begin{tabular}{|l|l|l|l|l|}
\hline \multicolumn{4}{|l|}{ Socio-economics status } & \\
\hline Social Support & High SES & Middle SES & Low SES & Total \\
\hline High social & 97.06 & 88.26 & 76.23 & 87.81 \\
Support & $(4.81)$ & $(4.87)$ & $(3.82)$ & \\
\hline Low social & 89.7 & 77.1 & 67.56 & 78.12 \\
Support & $(3.95)$ & $(3.89)$ & $(4.23)$ & \\
\hline Total & 93.38 & 82.68 & 71.89 & \\
\hline
\end{tabular}

Table 2: Showing 2x3 Analysis of Variance of Total Mental Health Test scores

\begin{tabular}{|l|l|l|l|l|}
\hline Source of Variation & Sum of square & Df & Ms & F-Ratio \\
\hline Social support (A) & 3699.20 & 1 & 3699.20 & $11.06^{* *}$ \\
\hline Socio-economic status (B) & 13846.07 & 2 & 6923.03 & $20.70^{* *}$ \\
\hline AB (Social support X SES) & 111.90 & 2 & 55.95 & .016 \\
\hline Within group (Error) & 58187.81 & 174 & 334.40 & \\
\hline Total & 175844.35 & 179 & & \\
\hline
\end{tabular}

*Significant at 0.05 Level, ** Significant at 0.01 Level

\section{DISCUSSION}

The data is analysed in the form of Mean, Combined Mean, Standard Deviation and ANOVA are computed separately. From the above result, it is clear that there is significant difference between mental health of high social support \& socioeconomic status and low social support \& socioeconomic status of college students. The present study is an exploratory one and it reveals several important facts which may beneficial to college students and to the society.

In total mental health scores of high social support students are found better than low social support. Social support is the physical and emotional comfort given to us by our family, friends, co-workers and others. There is good evidence that social support plays an important role in mental health or substance use problems. For example, people who are clinically depressed report lower levels of social support than people who are not currently depressed.

In total mental health scores of high socio-economic status students are found better than low socio-economic status. Mental health, health status and socioeconomic status are important determinants of an individual's wellbeing. Lower socioeconomic status is associated with decreased social network size and lower social integration (House et al., 1988; Thoits, 1995).

Good mental health can enhance one's life, while poor mental health can prevent someone from living a normal life. The consequences of these problems are likely to be significant and lasting, as mental disorders in early adulthood are associated with alcohol and substance abuse (Angst, 1996; Weitzman, 2004), academic success (Kessler, Foster, Saunders, \& Stang, 1995), and future employment and relationships (Ettner, Frank, \& Kessler, 1997; Kessler, Walters, \& Forthofer,

(c) The International Journal of Indian Psychology, ISSN 2348-5396 (e) | ISSN: 2349-3429 (p) | 169 
1998). Also without emotional support, mental health is at risk. Mental health of a person depends on Social support such as family, friends, relatives and socioeconomic status.

Nevertheless, it should be acknowledged that the result of this study are based on a limited sample of college students of sagar. It may useful to conduct study on larger sample of different areas of India for future research studies.

\section{Acknowledgments}

The author appreciates all those who participated in the study and helped to facilitate the research process.

\section{Conflict of Interests}

The author declared no conflict of interests.

\section{REFERENCE}

Amett, J. J. (2000). Emerging adulthood: A theory of development from the late teens through the early twentie. American Psychologist, 55,469- 480.

Angst, J.(1996). Comorbidity of mood disorders: A longitudinal prospective study. British Journal of Psychiatry Supplemental, 30,31-37.

Berkman, L. F,. Glass, T., Brissette, I., \&Seeman, T. E. (2000). From social integration to health: Durkheim in the new millennium. Social Science \&Medicine, 51, 843-857.

Buote, V. M., Pancer, S. M., Pratt, M. W., Adams, G., Bimie-Lefcovitch, S., Polivy, J, et al. (2007). The importance of friends: Friendship and adjustment among 1st-year university students. Journal of Adolescent Research, 22, 665-689

Coyne, J.C., \& Downey, G,(1991)Social factors and psychopathology: Stress, social support, and coping process. Annual Review of psychology, 42, 401-425.

Dalgard, O. S. (2008). Social inequalities in mental health in Norway: possible explanatory factors. International journal for equity in health, 7, 27.

Das, J., Quy-ToanDo, Q., Friedman, J., McKenzie, D., \& Scott, K. (2007). Mental Health and Poverty in Developing Countries: Revisiting the Relationship. Social Science and Medicine, 65:467-480.

Ettner, S. L., Frank, R. G., \& Kessler, R. C. (1997). The impact of psychiatric disorders on labor market outcomes. Industrial and Labor Relations Review, 51, 64-81.

Ferraro, K. F. (1999). Financial strain, social relation and psychological distress among older people: A cross-cultural analysis. Journal of Gerontology, 54, 3-15.

House, J. S., Umberson, D., \& Landis, K. R. (1988). Structures and processes of social support. Annual Review of Sociology, 14, 293-318.

Kawachi, I., \& Berkman, L. F. (2001). Social ties and mental health. Journal of Urban Health: Bulletin of the New York Academy of Medicine,78, 458-467. 
Kessler, R., Foster, C., Saunders, W., \& Stang, P. (1995). The social consequences of psychiatric disorders, I: Educational attainment. American Journal of Psychiatry, 152, 1026-1032.

Kessler, R., Walters, E., \& Forthofer, M. (1998).The social consequences of psychiatric disorders, III: Probability of marital stability. American Journal of Psychiatry, 155, 1092-1096

Koster, A., Bosma, H., Kemper, Pennix, Beekman, \& Deeg, et al. (2006). Socioeconomic differences in incident depression in older adult. The Role of psychological factors, physical health status, and behavioural factor. J psychosom Res, 61:619-27.

Letkowitz, E. S. (2005). “Things have gotten better”: Developmental changes among emerging adults after the transition to university. Journal of Adolescent Research, 20, 40-63.

Mojtabai, R., \& Olfson, M. (2004). Major depression in community dwelling middle aged and older adults; Prevalence and 2 and 4 year follow up symptom. psycol Med, 34:623-34.

Patel, V., \& Kleinman, A. (2003). Poverty and Common Mental Disorders in Developing Countrie. Bulletin of the World Health Organization, 81(8):609-615.

Rostad, B.,Deeg, \& Schei, B. (2009) socioeconomic in equalities in health in older women. European journal of ageing, 6:39-47.

Thoits, P. A. (1995)..Stress, coping, and social support processes: where are we? What next? Journal of Health and Social Behaviour, Extra Issue, 53-79

Weitzman, E. R. (2004). Poor mental health, depression, and associations with alcohol consumption, harm, and abuse in a national sample of young adults in college. Journal of Nervous and Mental Disease, 192, 269-277.

How to cite this article: Chaurasia K (2017), Effects of Social Support and Socioeconomic Status on Mental Health in College Students, International Journal of Indian Psychology, Volume 4, Issue 2, No. 85, ISSN:2348-5396 (e), ISSN:2349-3429 (p), DIP:18.01.020/20170402, ISBN: 978-1-365-68608-5 